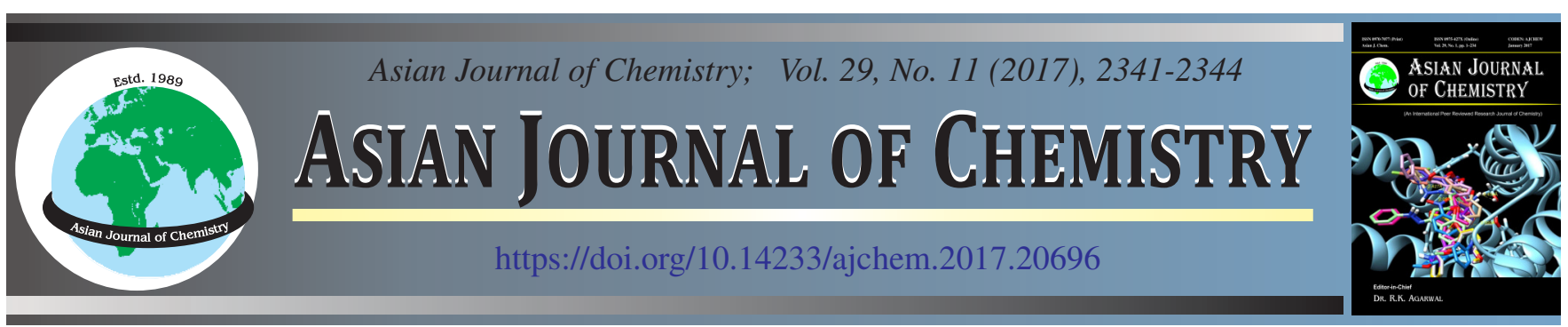

MINI REVIEW

\title{
Various Techniques to Optimize the Quality of Schottky Contacts on ZnO Thin Films: A Short Review
}

\author{
SUMIT VYAS
}

Department of Electronics and Communication Engineering, Thapar University, Patiala-147 001, India

Corresponding author: E-mail: sumit.vyas@thapar.edu; sumit.clooney@gmail.com

\begin{abstract}
Zinc oxide is a promising material for fabrication of electronic and optoelectronic devices. ZnO based Schottky diode is an important device that can be used for variety of applications. For a high quality Schottky contact on $\mathrm{ZnO}$, it is essential that the quality of the $\mathrm{ZnO}$ film should be very good. In this paper, various techniques that can be used to improve the quality of $\mathrm{ZnO}$ thin film and hence the quality of Schottky contacts on $\mathrm{ZnO}$ have been reviewed. Techniques like surface treatments of $\mathrm{ZnO}$, annealing of the film before and after deposition of the contacts, use of buffer layer and proper selection of deposition method greatly affects the quality of Schottky contact on $\mathrm{ZnO}$. These methods are reported by various research groups that are discussed in this paper.
\end{abstract}

Keywords: Schottky diode, Annealing, Schottky barrier, Detector, Ohmic, UV rays.

L

\section{INTRODUCTION}

Zinc oxide based Schottky diode is used for fabricating many important electronic and optoelectronic devices like photo-detector, transistors, gas sensors, etc. Mead [1] in 1965 reported the first Schottky contact to $\mathrm{ZnO}$. Till now a significant amount of work highlighting the important issues has been reported on Schottky contacts on ZnO. A good Schottky contact is charac-terized by very low series resistance with the semiconductor, a high rectification ratio, high thermal stability and a high barrier height. In general, the high work function metal such as Pd, Pt, Au, etc., are used for Schottky contact on $\mathrm{ZnO}$ thin films. Ideally, the Schottky barrier height $\Phi_{\mathrm{SB}}$ should be equal to $\left(\Phi_{\mathrm{M}}-\chi_{\mathrm{ZnO}}\right)$, but in real the measured $\Phi_{\mathrm{SB}}$ differs from ideal one. It is also found that barrier height is almost independent of the type of metal used for the contact. Most of the authors have reported the Schottky barrier heights in the range of 0.6-0.8 eV for the Schottky contacts fabricated on the $n$-type $\mathrm{ZnO}$ material [2]. The barrier height highly depends on the crystal quality, defects, surface treatments and deposition techniques. Also, the long-term stability of Schottky contacts to $\mathrm{ZnO}$ is one of the biggest challenges that are faced by the researchers. The poor performance of the contact is mainly due to the defects in the film that occurs due to the improper chemical bonding between $\mathrm{Zn}-\mathrm{O}$ during the deposition. The surface defects are even induced by the deposition of metal contacts [3]. Therefore, the film should be appropriately treated before and after the deposition of metal with proper methods to lowers the defects levels and improve the performance of the film. Various tech-niques like surface treatments of $\mathrm{ZnO}$, annealing of the film before and after deposition of the contacts, use of buffer layer, etc., have been reported by many researchers to improve the stability and performance of the contact.

Surface treatment of $\mathbf{Z n O}$ : The $\mathrm{ZnO}$ thin film consist of defects like oxygen vacancies $\left(\mathrm{V}_{\mathrm{O}}\right)$ and zinc interstitials $\left(\mathrm{Zn}_{\mathrm{i}}\right)$. These defects make $\mathrm{ZnO}$ electrically unstable and are responsible for the poor electrical characteristics of the device. These defects can be reduced by treating the surface of $\mathrm{ZnO}$ thin film by proper methods. Angadi et al. [4] studied the effect of oxygen $\left(\mathrm{O}_{2}\right)$ plasma treatment on epitaxial $\mathrm{ZnO}$ thin film. $\mathrm{Au} / \mathrm{ZnO} / \mathrm{ITO}$ structure was fabricated and the effect of $\mathrm{O}_{2}$ treatment on the I-V characteristics was studied. Before the $\mathrm{O}_{2}$ treatment, the sample exhibited ohmic behaviour but after the $\mathrm{O}_{2}$ treatment, the sample started showing rectifying I-V characteristics. The structural and surface morphology of the film were not much affected by the $\mathrm{O}_{2}$ treatment. The treatment resulted in the removal of conductive $\mathrm{OH}$ layer from $\mathrm{ZnO}$ surface that was confirmed by X-ray photoelectron spectroscopy (XPS). Oh et al. [5] used KrF laser to modify the Pt Schottky contact on $n$-type $\mathrm{ZnO}$ thin film. Before deposition of $\mathrm{Pt}$ contact, the $\mathrm{ZnO}$ film was treated with laser 
pulses in the presence of $\mathrm{O}_{2}$ at the pressure of $0.1 \mathrm{M}$ torr. The laser treated $\mathrm{ZnO}$ films were studied using Auger spectroscopy and cathode luminescence. The study revealed that the surface hydrogen and carbon compo-nents were removed after the treatment and also a reduction in sub-surface defects were observed. The $\Phi_{\mathrm{SB}}$ obtained by I-V and C-V studies were 0.73 $\mathrm{eV}$ and $0.85 \mathrm{eV}$, respectively. Lee et al. [6] reported the conversion of ohmic ITO contact to Schottky contact on $\mathrm{ZnO}$ films by the hydrogen peroxide treatment of $\mathrm{ZnO}$ surface. The $\mathrm{ZnO}$ film was deposited on an ITO-coated glass substrate by the continuous wave $(\mathrm{CW}) \mathrm{CO}_{2}$ LASER evaporation method. The calculated $\Phi_{\mathrm{SB}}$ was $1.16 \mathrm{eV}$, ideality factor was 2.31 and leakage current at $-3 \mathrm{~V}$ was $3 \times 10^{-7} \mathrm{~A}$. The photoluminescence study showed the reduction in the surface defects of $\mathrm{ZnO}$ film after the $\mathrm{H}_{2} \mathrm{O}_{2}$ treatment. The reduction in surface defects improved the diode characteristics. Nakamura and Temmyo [7] reported the surface treatment of $\mathrm{ZnO}$ film by boiling the $\mathrm{H}_{2} \mathrm{O}_{2}$ solution. $\mathrm{ZnO}$ films were deposited by remote-plasmaenhanced metal-organic chemical vapour deposition (RPEMOCVD) on a $\alpha$-plane sapphire subs-trate. Platinum metal was used to make Schottky contact on $\mathrm{ZnO}$ thin film. Before the deposition of platinum metal, the $\mathrm{ZnO}$ films were cleaned with acetone and methanol followed by rising in deionized water and drying with a nitrogen stream. After cleaning, the circular platinum contacts were patterned by standard lift-off photolithography. The platinum Schottky contacts were treated with $\mathrm{H}_{2} \mathrm{O}_{2}$ solution for $1 \mathrm{~min}$ at $100{ }^{\circ} \mathrm{C}$. The surface morphology of the film was studied using scanning electron microscope (SEM). The surface of the treated films was smoother as compared to the untreated films. By the transmission electron microscopy (TEM) analysis, it was observed that a very thin amorphous layer of $\mathrm{ZnO}_{2}$ of thickness 20-30 nm was formed over $\mathrm{ZnO}$ due to the $\mathrm{H}_{2} \mathrm{O}_{2}$ treatment. The sheet resistivity was increased from $2 \mathrm{k} \Omega$ /square to $1 \mathrm{M} \Omega /$ square. The high conductive $\mathrm{ZnO}$ layer was removed by the $\mathrm{H}_{2} \mathrm{O}_{2}$ treatment and high resistive $\mathrm{ZnO}_{2}$ layer was recovered. The non-treated sample was showing linear I-V whereas the treated sample exhibited excellent rectifying behaviour. Due to thin $\mathrm{ZnO}_{2}$ layer the rectifying behaviour of the diode was significantly improved. The rectification ratio at $\pm 3 \mathrm{~V}$ was in the order of $10^{6}$ and $\Phi_{\mathrm{SB}}$ was $0.78 \mathrm{eV}$. Yao et al. [8] prepared a ZnO-based Schottky diode using Ni/Au metal. The $\mathrm{ZnO}$ film was deposited by RF magnetron sputtering method. The $\mathrm{ZnO}$ thin films surface was etched by the dilute $\mathrm{HCl}$ solution for $20 \mathrm{~s}$ and also for $40 \mathrm{~s}$ to remove the defects induced from the ion-bombardment damages during the film deposition. The pre-etched $\mathrm{ZnO}$ layer surface was then dipped in the dilute $\mathrm{H}_{2} \mathrm{O}_{2}$ solution at $100{ }^{\circ} \mathrm{C}$ and dilute ammonium sulfide $\left(\left(\mathrm{NH}_{4}\right)_{2} \mathrm{~S}_{\mathrm{x}}\right)$ solutions at $60{ }^{\circ} \mathrm{C}$, respectively. The $\mathrm{Ni} / \mathrm{Au}$ $(20 / 100 \mathrm{~nm})$ metal was deposited on the modified $\mathrm{ZnO}$ film surface using electron-beam evaporation method. The current ratio (at $\pm 2 \mathrm{~V}), \Phi_{\mathrm{SB}}$ and ideality factor for non-etched film treated by $\mathrm{H}_{2} \mathrm{O}_{2}$ were $1035,0.68 \mathrm{eV}$ and 1.65 , respectively. The current ratio (at $\pm 2 \mathrm{~V}$ ), $\Phi_{\mathrm{SB}}$ and ideality factor for films pre-etched and treated by $\mathrm{H}_{2} \mathrm{O}_{2}$ for $20 \mathrm{sec}$ were $6923,0.83 \mathrm{eV}$ and 1.24 , respectively. The current ratio (at $\pm 2 \mathrm{~V}), \Phi_{\mathrm{SB}}$ and ideality factor for films pre-etched and treated by $\mathrm{H}_{2} \mathrm{O}_{2}$ for 40 s were $3.3 \times$ $10^{7}, 0.90 \mathrm{eV}$ and 1.20 , respectively. The current ratio (at $\pm 2 \mathrm{~V}$ ), $\Phi_{\mathrm{SB}}$ and ideality factor for films pre-etched and treated by
$\left(\left(\mathrm{NH}_{4}\right)_{2} \mathrm{~S}_{\mathrm{x}}\right.$ solution were $3.10 \times 10^{7}, 0.87 \mathrm{eV}$ and 1.3 , respectively. The Schottky barrier height of $\mathrm{H}_{2} \mathrm{O}_{2}$ treated $\mathrm{ZnO}$ layer contact to $\mathrm{Ni} / \mathrm{Au}$ was increased due to the compensation effect by the increase in $\mathrm{ZnO}$ and $\mathrm{OH}$ acceptors. The increase in the Schottky barrier height of $\left(\mathrm{NH}_{4}\right)_{2} \mathrm{~S}_{\mathrm{x}}$ treated $\mathrm{ZnO}$ thin film was due to the passivation of the $5 \mathrm{I}_{O}$ donors and $\mathrm{Zn}_{\mathrm{i}}$ acceptors due to the formation of the $\mathrm{Zn}-\mathrm{S}$ chemical bond. Tsiarapas et al. [9] studied the effect of hydrogen gas on the performance of $\mathrm{Au} /$ $\mathrm{ZnO}$ Schottky diode. The $\mathrm{ZnO}$ thin film was deposited using the DC-magnetron sputtering technique. Argon and hydrogen gases were used for the formation of the plasma. A significant improvement of the crystallinity of $\mathrm{ZnO}$ film was observed by varying the hydrogen concentration. At $\mathrm{H}_{2}$ concentration of $33.3 \%$, the resistivity of the film was lowest and has a value of $2.22 \times 10^{-4} \Omega \mathrm{cm}$. The corresponding value of Hall mobility and carrier concentration were $68.6 \mathrm{~cm}^{2}(\mathrm{~V} \mathrm{~s})^{-1}$ and $4.1 \times 10^{18}$ $\mathrm{cm}^{-3}$, respectively. The $\Phi_{\mathrm{SB}}$ was in the range of 0.72 to $0.82 \mathrm{eV}$ and the ideality factor was 1.42 .

Effect of annealing: There are many reports on related to the improvement in structural, optical, surface and electrical properties of $\mathrm{ZnO}$ thin film and devices by annealing [10-12]. Many groups have studied the effect of annealing on the electrical properties of $\mathrm{ZnO}$ thin film Schottky diode. Li et al. [13] reported the $\mathrm{ZnO}$-based UV detector with silver contact. The $\mathrm{ZnO}$ thin film and the Ag contact both were deposited by the pulse laser deposition method (PLD) using $\mathrm{KrF}$ excimer laser. The $\mathrm{Ag} / \mathrm{ZnO}$ was annealed for $2 \mathrm{~h}$ at $600{ }^{\circ} \mathrm{C}$. The ideality factor and barrier height of unannealed $\mathrm{Ag} / \mathrm{ZnO}$ film was 1.22 and $0.908 \mathrm{eV}$, respectively. After annealing at 600, the ideality factor and the barrier height was $0.988 \mathrm{eV}$ and is 1.18 . The improvement in the electrical properties of $\mathrm{Ag} / \mathrm{ZnO}$ was attributed to the annealing process. Mtangi et al. [14] investigated the effect annealing on the electrical properties of $\mathrm{Pd} / \mathrm{ZnO}$ Schottky diode in the presence of argon, hydrogen and oxygen gases. The ideality factor, $\Phi_{\mathrm{SB}}$ and series resistance for the unannealed sample were $1.43,0.72 \mathrm{eV}$ and $190 \Omega$, respectively. The ideality factor, $\Phi_{\mathrm{SB}}$, series resistance for samples annealed in $\mathrm{H}_{2}$ were $1.64,0.617 \mathrm{eV}$ and $70 \Omega$, respectively. The ideality factor, $\Phi_{\mathrm{SB}}$, series resistance for samples annealed in $\mathrm{O}_{2}$ were $1.57,0.545 \mathrm{eV}$ and $426 \Omega$, respectively. The ideality factor, $\Phi_{\mathrm{SB}}$ and series resistance for samples annealed in Ar were 1.75, $0.571 \mathrm{eV}$ and $79 \Omega$, respectively. The barrier height of the annealed samples decreased due to the increase in conductivity of the layer closer to the surface of $\mathrm{ZnO}$ that can be observed by the decrease in the series resistance. The deep level transient spectroscopy (DLTS) study revealed that the annealing process in the presence of $\mathrm{Ar}$ and $\mathrm{H}_{2}$ decrease the concentration of defects whereas annealing in the presence of $\mathrm{O}_{2}$ increases the surface defects. This can be attributed to $\mathrm{V}_{\mathrm{O}}$ or $\mathrm{Zn}_{\mathrm{i}}$, which are the most common defects formed in $\mathrm{ZnO}$ under oxygen rich environment. Gu et al. [15] reported the transformation of Ti/Ni/Ti/ $\mathrm{Au}$ Ohmic contact to Schottky contact on Al-doped $\mathrm{ZnO}$ thin films. The Al-doped $\mathrm{ZnO}$ thin films were deposited on a quartz substrate at $400{ }^{\circ} \mathrm{C}$ using PLD with a $\mathrm{KrF}$ excimer laser. Ti, $\mathrm{Ni}$ and $\mathrm{Au}$ contact metal layers of thickness $50 \mathrm{~nm}$ each was deposited sequentially using electron-beam evaporation method. The metal contacts were annealed at 200, 300, 400, 500, 600 and $700{ }^{\circ} \mathrm{C}$, respectively for $60 \mathrm{~s}$ in the nitrogen 
environment. These metal contact on $\mathrm{ZnO}$ exhibited ohmic nature and the resistivity decreased as the annealing temperature increased to $500{ }^{\circ} \mathrm{C}$. The resistivity of the as-deposited sample was $2.07 \times 10^{-4} \Omega \mathrm{cm}^{2}$ and decreased to $6.69 \times 10^{-5} \Omega$ $\mathrm{cm}^{2}$ at an annealing temperature of $500^{\circ} \mathrm{C}$. The transformation from ohmic to rectifying started above $600{ }^{\circ} \mathrm{C}$. At $600{ }^{\circ} \mathrm{C}$, the calculated barrier height was $0.57 \mathrm{eV}$. At $700^{\circ} \mathrm{C}$, cracks were appeared in the sample due to the release of inherent stress. Saw et al. [16] investigated the effect of annealing on Ni contact on $\mathrm{ZnO}$ thin films. The Ni contact was deposited using evaporation method on the sputtered $\mathrm{ZnO}$ thin films. The sample was annealed at $800{ }^{\circ} \mathrm{C}$. After annealing, the ohmic nature of $\mathrm{Ni} / \mathrm{ZnO}$ sampled transformed to rectifying nature. They assumed that the change in the electrical behaviour of the sample was due to the oxidation of $\mathrm{Ni}$ into $\mathrm{NiO}$ due to the annealing. This was confirmed by X-ray diffraction (XRD) studies where the spectra showed the peak of $\mathrm{NiO}$ at $37.296{ }^{\circ} \mathrm{C}$ along with the peaks corresponding to $\mathrm{ZnO}$.

Somvanshi and Jit [17] reported $\mathrm{Pd} / \mathrm{ZnO}$ thin film-based Schottky diodes with ideal Richardson constant and mean barrier height. The $\mathrm{ZnO}$ film was deposited on $n$-type Si substrate by vacuum thermal evaporation method. Before the deposition of metal, The $\mathrm{ZnO}$ film was treated with nitrogen gas for $30 \mathrm{~min}$ at $550{ }^{\circ} \mathrm{C}$. The treatment with $\mathrm{N}_{2}$ improves the crystalline quality of the film by minimizing the structural defects on $\mathrm{ZnO}$ thin film surface. The values of the effective Richardson constant and the zero-bias mean barrier height of the $\mathrm{Pd} / \mathrm{ZnO}$ Schottky diode were and $19.54 \mathrm{~A} \mathrm{~cm}^{-2} \mathrm{~K}^{-2}$ and $1.41 \mathrm{eV}$.

Yadav et al. [18] reported the effect of annealing on the properties of $\mathrm{ZnO}$ thin film and $\mathrm{Pd} / \mathrm{ZnO}$ Schottky diode. The $\mathrm{ZnO}$ film was grown by vacuum thermal evaporation process. $\mathrm{The} \mathrm{Pd} / \mathrm{ZnO}$ sample was annealed in the Ar atmosphere at 450, 550 and $650{ }^{\circ} \mathrm{C}$ temperatures, respectively for $20 \mathrm{~min}$. The $\mathrm{XRD}$ study revealed that the structural quality of the $\mathrm{ZnO}$ film improved with the increase in the annealing temperature to $550{ }^{\circ} \mathrm{C}$ and then the quality of the film degrades at $650{ }^{\circ} \mathrm{C}$. The barrier height, ideality factor and saturation current at $550{ }^{\circ} \mathrm{C}$ was $0.79 \mathrm{eV}, 1.58$ and $1.89 \times 10^{-9} \mathrm{~A}$ and were better that that $400{ }^{\circ} \mathrm{C}$. By further rise in temperature, the electrical parameters were found to degrade. The electrical properties were in good agreement with the structural properties. Recently, Al-Salman and Abdullah [19] reported the annealing effect on undoped $\mathrm{ZnO}$ thin film. The film was deposited by $\mathrm{RF}$ sputtering method at room temperature and at 200, 300 and $400{ }^{\circ} \mathrm{C}$, respectively. Palladium metal was used to form Schottky contact with the deposited $\mathrm{ZnO}$ film. The $\mathrm{Pd} / \mathrm{ZnO}$ samples were annealed at $500{ }^{\circ} \mathrm{C}$ for $2 \mathrm{~h}$ in the presence of $\mathrm{N}_{2}$ gas. The $\mathrm{Pd} / \mathrm{ZnO}$ samples deposited at $400^{\circ} \mathrm{C}$ showed excellent electrical properties after annealing as compared to the samples deposited at other temperature. The $\Phi_{\mathrm{SB}}$, ideality factor and leakage current of the unannealed sample deposited at $400{ }^{\circ} \mathrm{C}$ were $0.776 \mathrm{eV}$, 10.79 and $12.9 \mu \mathrm{A}$. After annealing at $500{ }^{\circ} \mathrm{C}$, the $\Phi_{\mathrm{SB}}$, ideality factor and leakage current were $0.77 \mathrm{eV}, 13.13$ and $0.17 \mu \mathrm{A}$.

Effect of buffer layer: The lattice mismatch between the substrate and $\mathrm{ZnO}$ thin film can induce defects in $\mathrm{ZnO}$ thin films. These defects are responsible for the instability and poor performance of Schottky contacts on $\mathrm{ZnO}$ thin films. One of the easy methods to reduce the lattice mismatch is to deposit the film on the pre-deposited seed layer or buffer layer. There are few reports present in the literature on $\mathrm{ZnO}$ Schottky diode using buffer layers. Hwang et al. [20] reported the $\mathrm{Au} / \mathrm{ZnO}$ Schottky diode using pre-annealed seed layer. The seed layer was deposited by two methods. First was the sol-gel method and the second was the hydrothermal method. The seed layer was annealed at $450{ }^{\circ} \mathrm{C}$ for $10 \mathrm{~min}$ in the presence of $\mathrm{N}_{2}$ gas. The $\mathrm{ZnO}$ layer was deposited on the annealed seed layer by hydrothermal method. The Au contact was deposited by thermal evaporation method. The $\mathrm{Au} / \mathrm{ZnO}$ grown on sol-gel deposited seed layer exhibited ohmic characteristics whereas the same exhibited excellent rectifying properties on the seed layer deposited by hydrothermal method. The rectification ratio of $\mathrm{Au} / \mathrm{ZnO}$ Schottky diode at $\pm 2 \mathrm{~V}$ was 8000 . The $\Phi_{\mathrm{SB}}$ of $\mathrm{Au} /$ $\mathrm{ZnO}$ Schottky diode was $0.79 \mathrm{eV}$ and a series resistance $\left(\mathrm{R}_{\mathrm{s}}\right)$ of $13.88 \mathrm{kU}$. Somvanshi and Jit [21] reported the effects of $\mathrm{Zn}$ and $\mathrm{Sn}$ buffer layers on the rectifying behaviour of $\mathrm{Pd} / \mathrm{ZnO}$ Schottky diodes. The $\mathrm{ZnO}$ thin film, buffer layers and the Pd contact both were grown by thermal evaporation method. The value of rectification ratio, $\Phi_{\mathrm{SB}}$ and ideality factor for $\mathrm{Pd} / \mathrm{ZnO}$ Schottky diode without buffer layer were $113,0.67 \mathrm{eV}$ and 2.36. The value of rectification ratio, $\Phi_{\mathrm{SB}}$ and ideality factor for $\mathrm{Pd} / \mathrm{ZnO}$ Schottky diode with Sn buffer layer were 885, 0.75 $\mathrm{eV}$ and 2.67. The value of rectification ratio, $\Phi_{\mathrm{SB}}$ and ideality factor for $\mathrm{Pd} / \mathrm{ZnO}$ Schottky diode with $\mathrm{Zn}$ buffer layer were $7561,0.78 \mathrm{eV}$ and 2.10. The series resistance of $\mathrm{Pd} / \mathrm{ZnO}$ Schottky diode without buffer layer, with $\mathrm{Sn}$ seed layer and Zn seed layer was $4734 \Omega, 4637 \Omega$ and $1677.7 \Omega$, respectively. Clearly $\mathrm{Pd} / \mathrm{ZnO}$ thin film Schottky diodes with Zn buffer layer exhibited excellent rectifying properties as compared to $\mathrm{Pd} /$ $\mathrm{ZnO}$ Schottky diode without seed layer and Sn seed layer.

Effect of deposition method: The properties of $\mathrm{ZnO}$ thin film is highly affected by the deposition technique used. There are very less reports present in the literature that compares the effect of deposition techniques on the properties of $\mathrm{ZnO}$ thin film. Aal et al. [22] used sol-gel and thermal evaporation method for depositing $\mathrm{ZnO}$ thin films. They observed that $\mathrm{ZnO}$ thin films deposited by the sol-gel method have more surface roughness and larger grain size as compared to thermally evaporated $\mathrm{ZnO}$ films calcined at same conditions. XRD analysis revealed that the $\mathrm{ZnO}$ film deposited by the sol-gel method has preferred orientation along 002 plane whereas $\mathrm{ZnO}$ film deposited by thermal evaporation method was polycrystalline in nature with orientation along 100, 002 and 101 planes, respectively. Singh and Chakrabarti [23] deposited $\mathrm{ZnO}$ thin films by three different techniques e.g., sol-gel derived, thermal oxidation of pre-deposited metallic zinc ( $\mathrm{Zn}$ ) and RF sputtering method. The optical, structural and electrical properties of the $\mathrm{ZnO}$ films by different deposition techniques were studied by using various characterization techniques and were systematically compared. They observed significant differences in optical, structural and electrical properties of the $\mathrm{ZnO}$ films by three deposition techniques. The structural properties of $\mathrm{ZnO}$ films obtained by oxidation of pre-deposited zinc were much better than those obtained by RF-sputtering and sol-gel. The electrical and optical properties of thermally oxidized $\mathrm{ZnO}$ film was found to be good enough as compared to $\mathrm{ZnO}$ films by sol-gel and RF sputtering for fabrication of electronic and 
optoelectronic devices. Similarly, Vyas et al. [24] compared the properties of $\mathrm{ZnO}$ thin films that were deposited on p-type $\mathrm{Si}$ $<100>$ substrate and glass substrate using thermal evaporation, PLD and RF sputtering method. Their XRD result revealed that the as-deposited $\mathrm{ZnO}$ thin films by thermal evaporation and PLD method were polycrystalline in nature. The $\mathrm{ZnO}$ film by thermal evaporation method had major orientation in (101) plane and the $\mathrm{ZnO}$ film deposited by PLD process has major orientation in (002) plane. The films deposited by RF sputtering method had orientation along a single plane (002). The AFM studies revealed that the $\mathrm{ZnO}$ film by $\mathrm{RF}$ sputtering method had larger grain size with smoother surface as compared to the $\mathrm{ZnO}$ film by thermal evaporation and PLD method. The band gap was found to be around $3.2 \mathrm{eV}$. The transparency in the visible region for films obtained by PLD and RF sputtering method was better than that of the film obtained by thermal evaporation method. The electrical properties of $\mathrm{Pd}: \mathrm{Au} / \mathrm{ZnO}$ (RF sputtered) was better as compared to electrical properties of Pd:Au/ZnO (PLD and thermally evaporated). The better quality of RF sputtered $\mathrm{ZnO}$ thin film was attributed to the fact that RF sput-tering method results in a uniform deposition over a large area whereas by thermal evaporation and PLD method it is not possible.

\section{Conclusion}

Zinc oxide thin films are polycrystalline in nature and various factors like grain boundary, crystal defects in $\mathrm{ZnO}$ thin film and instability of electrical properties of $\mathrm{ZnO}$ thin films in ambient oxygen affects the performance of $\mathrm{ZnO}$ Schottky diode. The performance can be enhanced by treating $\mathrm{ZnO}$ thin film with various methods like surface treatment, annealing, insertion of buffer layer, etc. All these methods improve the crystal quality and reduce the defects in $\mathrm{ZnO}$ thin film. By choosing proper deposition methods, it is also possible to achieve a single crystalline $\mathrm{ZnO}$ thin film. A high quality $\mathrm{ZnO}$ thin film is required for fabricating high performance $\mathrm{ZnO}$ Schottky diode. The performance of $\mathrm{ZnO}$ based Schottky diode can be further improved by post metallic deposition treatment like annealing and surface treatment in presence of various gasses.

\section{REFERENCES}

1. C.A. Mead, Phys. Lett., 18, 218 (1965); https://doi.org/10.1016/0031-9163(65)90295-7.

2. L. Brillson and Y. Lu, J. Appl. Phys., 109, 121301 (2011); https://doi.org/10.1063/1.3581173.

3. H.L. Mosbacker, S. El Hage, M. Gonzalez, S.A. Ringel, M. Hetzer, D.C. Look, G. Cantwell, J. Zhang, J.J. Song and L.J. Brillson, J. Vac. Sci. Technol. B, 25, 1405 (2007); https://doi.org/10.1116/1.2756543.
4. B. Angadi, H.C. Park, H.W. Choi, J.W. Choi and W.K. Choi, J. Phys. D Appl. Phys., 40, 1422 (2007); https://doi.org/10.1088/0022-3727/40/5/016.

5. M. Oh, D. Hwang, J. Lim, Y. Choi and S. Park, Appl. Phys. Lett., 91, 042109 (2007); https://doi.org/10.1063/1.2764436.

6. H. Lee, C. Su, B. Wu, W. Xu, Y. Lin and M. Chern, Jpn. J. Appl. Phys., 50, 088004 (2011).

7. A. Nakamura and J. Temmyo, J. Appl. Phys., 109, 093517 (2011); https://doi.org/10.1063/1.3582143.

8. R.-H. Chang, K.-C. Yang, T.-H. Chen, L.-W. Lai, T.-H. Lee, S.-L. Yao and D.-S. Liu, J. Nanomater., Article ID 560542 (2013); https://doi.org/10.1155/2013/560542.

9. C. Tsiarapas, D. Girginoudi and N. Georgoulas, Semicond. Sci. Technol., 29, 045012 (2014); https://doi.org/10.1088/0268-1242/29/4/045012.

10. X.Q. Wei, Z.G. Zhang, M. Liu, C.S. Chen, G. Sun, C.S. Xue, H.Z. Zhuang and B.Y. Man, Mater. Chem. Phys., 101, 285 (2007); https://doi.org/10.1016/j.matchemphys.2006.05.005.

11. O. Lupan, T. Pauporte, L. Chow, B. Viana, F. Pelle', L.K. Ono, B.R. Cuenya and H. Heinrich, Appl. Surf. Sci., 256, 1895 (2010); https://doi.org/10.1016/j.apsusc.2009.10.032.

12. X. Jiang-Ping, S. Shao-Bo, L. Lan, Z. Xiao-Song, W. Ya-Xin and C. XiMing, Chin. Phys. Lett., 27, 047803 (2010);

13. X.-K. Li, Q.-S. Li, D.-C. Liang and Y.-D. Xu, Optoelectron. Lett., 5, 216 (2009); https://doi.org/10.1007/s11801-009-8216-6

14. W. Mtangi, F.D. Auret, W.E. Meyer, M.J. Legodi and P.J. Janse-vanRensburg, J. Appl. Phys., 111, 094504 (2012); https://doi.org/10.1063/1.4709728.

15. J.L. Gu, Y.F. Lu, J. Zhang, L.X. Chen and Z.Z. Ye, J. Alloys Comp., 556, 62 (2013); https://doi.org/10.1016/j.jallcom.2012.12.104

16. K.G. Saw, S.S. Tneh, G.L. Tan, F.K. Yam, S.S. Ng and Z. Hassan, PLoS One, 9, e86544 (2014); https://doi.org/10.1371/journal.pone.0086544.

17. D. Somvanshi and S. Jit, IEEE Trans. Electron Dev., 34, 1238 (2013); https://doi.org/10.1109/LED.2013.2278738.

18. A.B. Yadav, K. Singh, A. Pandey and S. Jit, Superlattices Microstruct., 71, 250 (2014); https://doi.org/10.1016/j.spmi.2014.03.043.

19. H.S. Al-Salman and M.J. Abdullah, Chin Shu Hsueh Pao, 28, 230 (2015); https://doi.org/10.1007/s40195-014-0189-1.

20. J. Hwang, C. Kung and Y. Lin, IEEE Trans. NanoTechnol., 12, 35 (2013); https://doi.org/10.1109/TNANO.2012.2226188.

21. D. Somvanshi and S. Jit, IEEE Electron Device Lett., 35, 945 (2014); https://doi.org/10.1109/LED.2014.2334473.

22. A.A. Aal, S.A. Mahmoud and A.K. Aboul-Gheit, Nanoscale Res. Lett., 4, 627 (2009); https://doi.org/10.1007/s11671-009-9290-1.

23. S. Singh and P. Chakrabarti, Superlattices Microstruct., 64, 283 (2013); https://doi.org/10.1016/i.spmi.2013.09.031.

24. S. Vyas, P. Giri, S. Singh and P. Chakrabarti, 44, 3401 (2015); https://doi.org/10.1007/s11664-015-3861-y. 